\title{
Do Similar Brands 'Like' Each Other? An Investigation of Homophily Among Brands' Social Networks on Facebook
}

\author{
Mohammad Hatim Abuljadail ${ }^{1}$, Gi Woong Yun ${ }^{2} \&$ Saeed Ali Badghish ${ }^{3}$ \\ ${ }^{1}$ Faculty of Communication and Media, King Abdulaziz University, Jeddah, Saudi Arabia \\ ${ }^{2}$ Reynolds School of Journalism, University of Nevada, Reno, USA \\ ${ }^{3}$ Faculty of Economics and Administration, King Abdulaziz University, Jeddah, Saudi Arabia \\ Correspondence: Mohammad Hatim Abuljadail, Faculty of Communication and Media, King Abdulaziz \\ University, Jeddah, Saudi Arabia. E-mail: mabuljadail@kau.edu.sa
}

Received: June 25, 2019 Accepted: August 6, 2019 Online Published: August 19, 2019

doi:10.5539/ijms.v11n3p63 URL: https://doi.org/10.5539/ijms.v11n3p63

\begin{abstract}
The advent of internet and communication technologies enabled marketers of brands to have more ways to communicate with their audience; one of which is connecting with other brands. One of the most popular outlets that allow brands to connect with other brands online is Facebook. Brands on Facebook can establish an official fan page where they can interact with their fans as well as network with other brands' official Facebook pages through "liking" them. This paper seeks to investigate the "liking" behavior among local and global brands (brand to brand) on Facebook in Saudi Arabia and whether these brands' "liking" network is based on homophilous relationships. The results showed that both status (e.g., geography and gender), and value (e.g., family ties and religion) homophilous relationships are in play. However, value homophily was a strong factor in brands' network in Saudi Arabia for some brands in the absence of status homophily network. Although status homophily in general played a role, geographical proximity was not a strong factor compared to previous reports on social network analysis. The data for this study were obtained from 40 brands marketed in Saudi Arabia. Using Netvizz and Gephi, network structures were mapped to explore the relationships among the brand's' Facebook pages.
\end{abstract}

Keywords: homophily, brands, social networks, marketing, Facebook

\section{Introduction}

In today's global context, brands can mobilize across borders having branches worldwide. Not only do brands exist globally, but they also carry a much stronger influence on each other than ever. Many studies have shown that brands have values, identities, image, personality, opinions and friendships much like an individual (Phillips, McQuarrie, \& Griffin, 2014). Also, like individuals, brands play a unique role in our society and this role depends on cultural and relational aspects (Kapferer, 2004). For example, perception on global brands, e.g., McDonald's or M\&M's, in the United States can be vastly different in the Middle East. In the age of social network, those perceptions on brands are expressed on social network through the relationships between fans and brands. This relationship is particularly interesting observing the success of some brands in the contemporary global networked society. Those brands often successfully take advantage of the existing brand networks. Brands which are connected with each other can take advantage of the network among themselves and get more intricate network of online friendship to promote their brands. Thus, brands often try to network with other brands on the top of their relationship goal, i.e., directly networking with consumers. Because the interconnected relationships can influence the image of the brand as well as how consumers perceive one brand to another, it is important to understand the relationships and how these relationships evolve with whom they involve with.

In addition, the emergence of social media and communication technologies enabled brands to have more ways to reach their consumers around the world. Consumers around the globe are able to see what global brands are communicating and who they are associated with. There are many cases where brands have to associate with partners that might not be appealing to consumers around the world. For example, the 2005 boycott of Arla, a Scandinavian dairy brand, in the Arab world, was due to their affiliation with an anti-Islam publication, Jyllands-Posten. Though the brand itself was not responsible for the publication, their mere association with it 
negatively affected their brand image and cost them years of sales (Mahajan, 2013).

Understanding how consumers perceive brands and how brands portray themselves is important. It is also important to understand whom they associate with, if they associate with brands outside of their geographic region or brands in different industries - especially in today's globalized world, where it is not easy for marketers to be aware of all the cultural and political differences among countries where their brands exist. If brands mirror the individual through their characteristics as an entity, they could also gravitate toward similar entities that have similar characteristics. This can be quite similar to the way people network with each other. This study seeks to understand whether homophilous (value vs. status) relationships exist among brands in the virtual word through analyzing and visualizing the social networks of brands' Facebook pages. Homophilous relationships could include relationships that are based on sharing the same religion, ethnicity and language. To make sure the study maximizes the inclusion of such cases, the authors examine both local and global brands in a society made of a conservative religious value, Saudi Arabia.

\subsection{Social Network Analysis and Visualization}

Social networks are established whenever individuals interact directly or indirectly with other individuals, organizations or artifacts (Hansen, Schneiderman, \& Smith, 2010). Social network analysis can visualize complex relationships on maps; it is also capable of measuring the size, shape, and density of social networks. Social network studies differ from other social science research methods that they explore connections between agents and such analysis can reflect a broader image of the society (Hansen, Schneiderman, \& Smith, 2010). Network analysis examines all the entities and ties among the network and calculates measures that describe the locations and importance of each entity in the network of relationships. Social network analysis is capable of analyzing social networking sites (SNS), such as Facebook, and visualizing the connections of entities based on mathematical calculations and graphical language that can explain network relations of individuals, groups, and events (Hansen, Schneiderman, \& Smith, 2010).

There are tools, such as NodeXL and Gephi that are designed to enable researchers to analyze social networks. Such analysis can provide beneficial insight to researchers and practitioners. In addition to the tools used to analyze networks, there are tools that enable researchers to extract data from SNS. Typical JSON data sources are often to everyone in the cases of open social network systems, e.g., Twitter. Other closed social network systems sometimes allow data access applications. For instance, Facebook allows an application such as Netvizz for researchers to download Facebook data and Ncapture does similar function for Youtube comment data.

\subsection{Brand Identity, Association and Relationships}

In marketing, brands are used to differentiate and distinguish between products (Uggla, 2006). Besides products, brands are also used for companies, persons, places, organizations and symbols (De Chernatony, 2001). Kapferer (2004) suggests that brands are also identified with cultural aspects. Brands that are established under the umbrella of a company will most likely reflect the culture of the company and its core values. For example, Hobby Lobby (U.S. based brand) has been reflecting American Christian values as was apparent in the controversy when the brand chose not to cover certain reproductive health care expenses for their employees that conflicted with their Christian values (Fuller, 2014).

Brand identity can also be promoted or established in associations with other brands to broaden their market share and fan base (Uggla, 2006). For example, Adidas (Adidas Group, http://www.adidas-group.com/) sponsored the New Zealand All Blacks rugby team to reach a new audience (Motion et al., 2003). However, the decision to associate with a specific brand should depend on many different factors such as a mutual goal and should be carefully made to avoid any accidental negative association. Indeed, the more connections may lead to more precarious associations due to the uncontrollable nature of associated brands. Brands should thoughtfully evaluate both the positive and the negative effects of that relationship when making connections or associations. Contemporary digital environments enable brands' existence on social media and, often, brands on social media endorse each other to achieve mutual benefits. The emergence of social media allowed almost all known brands to have official Facebook fan pages and, through these pages, brands can connect with each other through "like" network (Abuljadail, Ha, Wang, \& Yang, 2015). The diffusion of such network relationships demands more research in this area.

\subsection{Social Media and Facebook Page "Like" Network}

The growing popularity of social media, such as Facebook, has a notable effect on the lives of individuals (Xu, Ryan, Prybutok, \& Wen, 2012). Since 2015, more than one billion people used Facebook in one day (Facebook, 2015). Facebook's popularity has attracted companies to use Facebook as a new brand promotion channel. The 
strategies to attract more people to "like" retailers' Facebook pages play an important role in many companies' marketing plans. Facebook fan pages are like users' personal profiles, but are designed for organizations, and they are open to the public. Users and organizations can become fans or follow the brands' Facebook page by clicking the "like" button on the page. Companies could develop new customers, make existing customers more loyal, and interact with their fans through Facebook fan pages. Brands' Facebook fan pages can provide texts, sale announcements, discounts, advertisements, videos or links about their products or services to their fans. Subsequently, their fans can interact with other fans or with the organization itself. Fans' participation in a brand's fan pages automatically appears in fans' news feed and in their friends' news feed as well, which becomes free word-of-mouth promotion for retailers or brands (Hu et al., 2013). In addition, Facebook fan pages provide various communication tools such as liking, sharing, and posting comments. Individuals could use these features to interact with other fans who share the same interests, which might lead to sharing, liking, or re-posting messages that promote the brand. This interaction with other fans who share the same interest could encourage fans to participate more in the fan page.

Unlike personal Facebook accounts or pages, Facebook official fan pages can only like other official fan pages. In other words, they can't like personal pages. For example, if an administrator of an official brand Facebook fan page logged in as an administrator instead of a personal username, they are only allowed to "like" other fan pages. Fan pages can view individual Facebook users' personal profiles but they can't like them. All the fan pages "liked" by a fan page appears on the left side of the Facebook fan page under a section called "liked by this page". Then, anyone viewing the page, even without liking it, will be able to see the "liked by this page" section. Fans can check those pages "liked" by the page to see potential similar pages that they could like and, also, competitors can monitor those pages.

Another important function that is based on the "liked by this page" section is the Facebook recommendation system. Facebook monitors what people and pages "like" and then recommends pages that are similar to the pages liked. This unexplored area or page like network among brands can be important to marketers. They need to understand the implication of this function to marketers. Some brands could "like" their competitors in order to monitor their social media behavior; however, doing so could promote the competition in the brand's page because fans can see the "liked by this page" section. Decision of not "liking" pages could limit what brands can see on their Facebook feeds as well as what Facebook can recommend to them and to their potential fans. Because the "liked by this page" Facebook function could be an important marketing tool, this research will focus on exploring the 'like' network among brand's Facebook fan pages and examining whether these links are based on homophilous relationships, such as status versus value homophilies.

\subsection{Homophily}

The idea of homophily is that similar individuals contact each other at a higher rate than dissimilar individuals; similarities such as behaviors and cultures, reflect on the distance among individuals in the network as well as on the rate of how information travels from one point to another (McPherson, Smith-Lovin, \& Cook, 2001). Previous studies have examined how individuals have different characteristics and people tend to find others who have similar characteristics and establish relationships with them (Stearns, Buchmann, \& Bonneau, 2009). There are two different types of homophily that were identified by Lazarsfeld and Merton in 1954; status and value. Status homophily refers to similarities in socio-demographic characteristics such as race, ethnicity, sex, age, and acquired characteristics such as education, occupation and behavior patterns (McPherson et al., 2001). Value homophily focuses on similarities based on values, attitudes and beliefs and it includes many different internal states that shape individuals' orientation toward future behavior, such as religion and family (Marx \& Spray, 1972).

This study compares connections that are based on value and status homophily. In this study status homophily are social network connections that are based on attributes such as geography, gender, and industry. On the other hand, value homophily refers to social network connections that are based on values and beliefs, such as religion and family ties. McPherson and colleagues (2001) posited geography as the most influential factor that causes homophilous relationships to shape, which increases the likelihood of connecting with those who are within close geographic proximity. Although the advancement of the internet has made it easier to maintain relationships over long distances by making communication easier and faster, geographical location is still the primary source of relationships, even for those who have high speed internet access. Previous research has shown that in the age of digital media, the importance of geographic closeness has not been diminished and even those who depend greatly on technology for communication still primarily associate with those who are in close proximity (Wellman, 1996). 
Another source of status homophily relevant to this research is the types of industry. Many brands are categorized based on the nature of the industry they are in. For example, Ford, Toyota, and BMW are categorized under the automotive industry and share the same nature of product category. Although they have different origins of the country and their specific target consumers, they are in the same industry and are therefore connected via homophilous network, i.e., status homophily network. Similar activities and interests among similar industry types are important factors in relationship building (McPherson et al., 2001).

In the contexts of Saudi Arabia's social network, gender is another particularly important status homophily factor. Brands are often identified with gender. Some brands, e.g., Lancome, Olay and Mikyajy, are targeting women as they are specialized in beauty supplies and makeup. In the same way, other brands such as Alshiaka (men's traditional clothing brand) are identified with men. Previous research shows that there is a homophilous relationship based on gender in social network. It is reported that women are more likely to have homophilous relationships with other women while men are more likely to have relationships with both men and women (McPherson et al., 2001).

In contrast to status homophily, value homophily aspects, such as religion and family, look at the homophilous network from the values or ideas people possess. Relationships among individuals or agents who share the same religion are more likely to be stronger than those with different religions (McPherson et al., 2001). Many brands often have identities and associations with different cultural values. While religion plays an important role in relationships on the individual level, for the purposes of this research, it will also be considered on the brand level because the brands in this study are local and global brands that exist in a community that is based on religion-Saudi Arabia. Cultural values in Saudi Arabia are mainly based on Islam, which makes it a good candidate to investigate homophilous relationships based on religion. Stone (2002) states that "whatever is happening in the Islamic world, whether in its collective manifestations or individual Islamic countries and populations, is a product of the commonality of attitudes and sentiments, which Islam imposes" (p. 123).

Family ties are another important source for value homophily. Individuals are connected to other individuals who are related to them through familial ties, parents, siblings, relatives, and others. As individuals have family ties, brands have such relations as well. For example, Coca Cola, Fanta, and Sprite are all owned by the same parent company, Coca Cola (Uggla, 2006). However, family ties can produce homophilous relationships that are similar and different at the same time (McPherson et al., 2001). They are similar in terms of sharing the same goal, but can be different in gender-based branding, location-based strategies, or appeal to religion. Family value homophily is probably more important than other homophilous relationships because brands that are connected through family ties may ultimately share a common loyalty toward the parent brand. While one brand might have a homophilous relationship with another brand from another company based on similar characteristics, it will still maintain a stronger tie to brands that might be different but connected through family ties. Saudi Arabia according to Badghish, Stanton and $\mathrm{Hu}$ (2018), is a country with collectivistic culture and highly values family connections. Having active Saudi local brands and other global brands competing in the country with strong religion and family values makes Saudi Arabia a good place to examine homophilous relationships based on familial ties. With the discussed concepts in mind, this study proposes below research question.

\section{RQ: Do status and value homophilous relationships exist among brand's' Facebook pages in Saudi Arabia?}

\section{Method}

Facebook application, Netvizz, extracted Facebook data for this study. One of the datasets that could be extracted is the 'page-like' network. This tool creates a network that reflects the connections between official Facebook pages based on the 'likes' between them. The module provided by Netvizz starts from the page the researcher decides to start from (the seed) and then it retrieves all the pages that the chosen page (the seed) likes. This option can provide 1.5-depth page-like network, which means that the researcher will get a data that includes the pages that are connected to the chosen page (the seed) through likes as well as the pages that are connected to those pages that like the chosen pages. In other words, only the chosen page's friends' network data is provided in 1.5 edge network. This data set also shows the directions of the likes: if 'likes' are one-sided or two-sided, and if one-sided, what side is the one who clicked the 'like' button. The directional edge network data can provide an opportunity to examine the reciprocal nature of edge network among the sample Facebook page network.

The Facebook fan page data extracted through Netvizz was viewed and graphed on Gephi. This study used a quota sample of twenty local brands and twenty global brands that exist in Saudi Arabia. Twenty brands from the list of the most popular Saudi brands in 2013 and another twenty global brands were selected from the most valuable global brands in 2014 (see appendix A). A purposive quota sample method was used to select the brands based on their industry as well as their active presence on Facebook. After choosing a total of forty Facebook 
pages the authors used brandirectory.com to verify the country of origin and industry of brands.

The Facebook data set included the "page like network" of the forty brands showing how pages are connected through the "likes" between them. These "likes" were treated as edges and Facebook pages were treated as nodes. The study took advantage of the maximum number of edge data collection, two degrees of separation from each Facebook page, on every data collection session. In total, to create Facebook page like network, the 40 separate datasets, for 40 brands, were collected. Later, the collected datasets were merged into one dataset to detect and graph the "like" network of the collected Facebook pages. The duplicate edges, due to the redundant data collection among 40 brands, of the merged datasets were cleaned after merging the datasets. Without those duplicate edges, the dataset contained 8,084 unique pages (nodes). The last data cleaning process eliminated the nodes that were not related to this research (e.g., book authors, books, non-profit organizations, and other non-brand related pages) and the nodes in smaller networks that were not connected to the main network (giant component) were excluded because this study is examining a network where all the nodes are connected to each other directly or indirectly. At the end, 450 nodes, i.e., Facebook pages, were analyzed in this research. All the nodes were within 10 industry categories: automotive, food/beverage, technology, beauty supplies, clothing, consumer goods, financial services, media, retail and telecommunications. Graphs were obtained through Gephi to explore the homophilous relationships in the network.

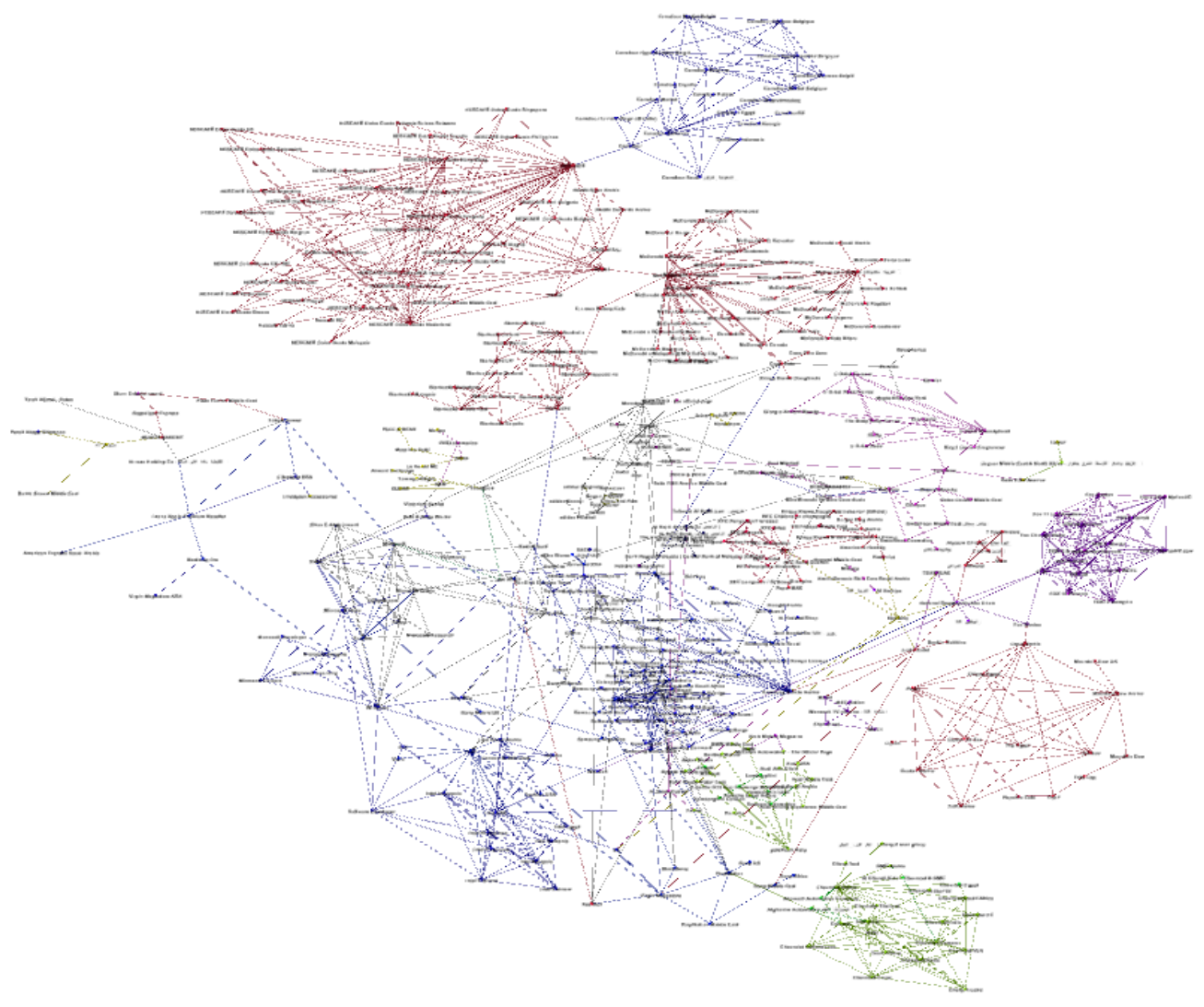

Figure 1. Note: This graph shows the visualization of the complex network (450 nodes)

\section{Results}

The results have several important implications for social media marketing. Brands were examined to see if they connect to other brands based on status homophily (e.g., geography and gender) as well as value homophily (e.g., religion and family), to answer the research question that seeks to investigate whether status and value homophilous relationships exist among brands on Facebook in Saudi Arabia. The results show that brands marketed in Saudi Arabia connect to other brands based on both status and value homophily factors. However, value homophilous relationships based on familial ties are the most prominent type of homophily that connects brands together in Saudi Arabia. Familial ties were found to be the most common source for homophilous 
relationships, namely - for global brands. Global brands, such as McDonald's were more likely to have relationships with other brands that fell under the parent company. This type of relationship was found not only in the food and beverage industry but across different industries, such as technology, automotive, financial services, retail, and media (see Figure 2).

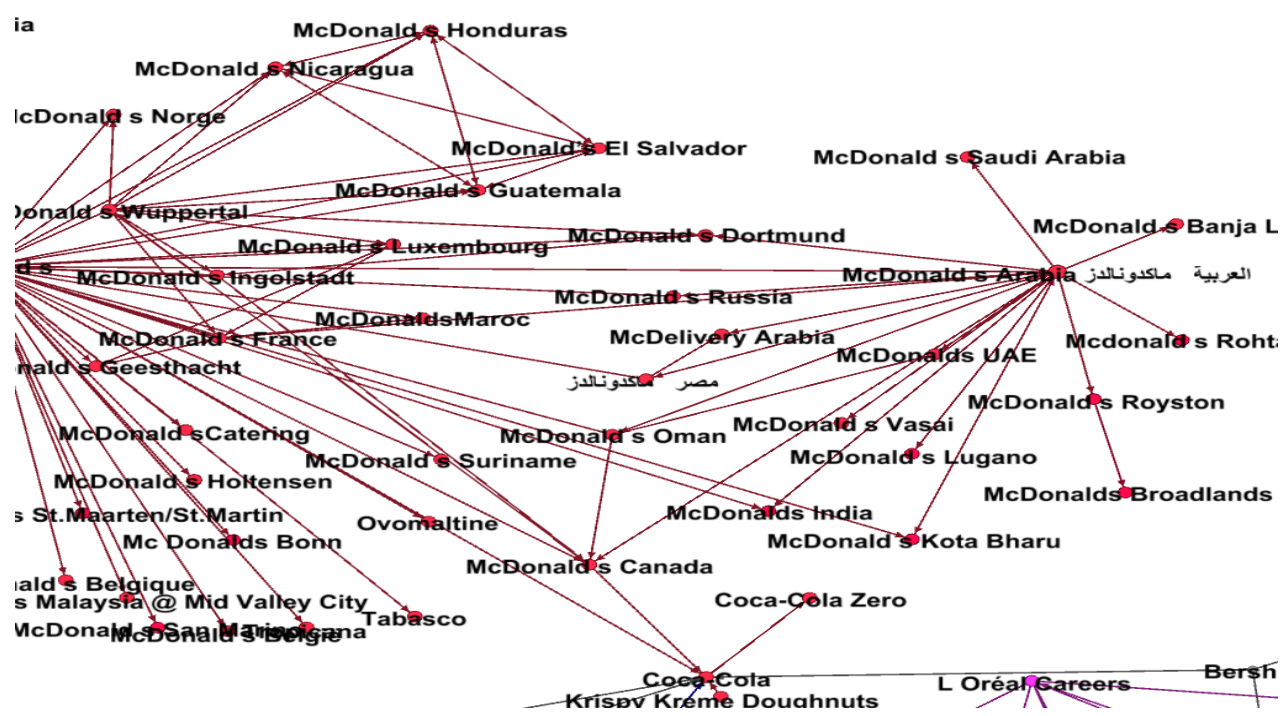

Figure 2. Close-up on McDonald's family-based network

In regards to the other sources of homophilous relationships, industry was also found to be a factor for homophilous relationships but not as common as family. It is apparent that when brands do not fall under a parent company, they are more likely to connect with other brands based on different factors such as industry. As shown in Figure 3, different automotive brands (i.e., Porsche, Bugatti, Bentley, Audi, McLaren, BMW, Ferrari, Lamborghini, Maserati, Aston Martin, Rolls-Royce, Gold Rush Rally, and Samaco Automotive) are connected with other brands that are in the automotive industry. Besides the industry, Figure 3 shows that those brands are connected based on the industry mainly and the area or continent of origin as well. All the automotive brands in Figure 3 are European brands. This emphasizes the importance of geographic homophilous relationships.

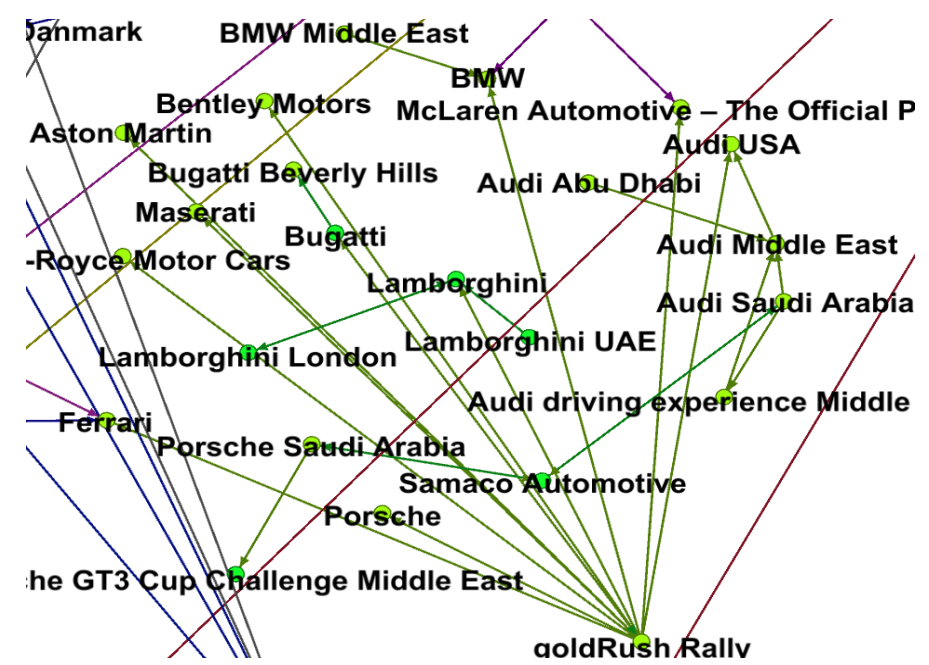

Figure 3. Close-up on industry-based network (automotive)

Gender was also found as a factor of homophilous relationships. Figure 4 shows that beauty supply brands are connected to other brands that are associated with women, such as makeup and other beauty supply brands (L'Oreal, Giorgio Armani Beauty, Lancome, Garnier, Maybelline New York, Paul Mitchell, Ralph Lauren 
Fragrances, Wojooh Beauty, Clarisonic, The Body Shop, Sephora, Clinique, Estee Lauder, Philosophy, Smashbox, BareMinerals, and Vichy). The majority of the brands are beauty supply products, which might also show the industry as an important factor here even with the presence of the gender factor.

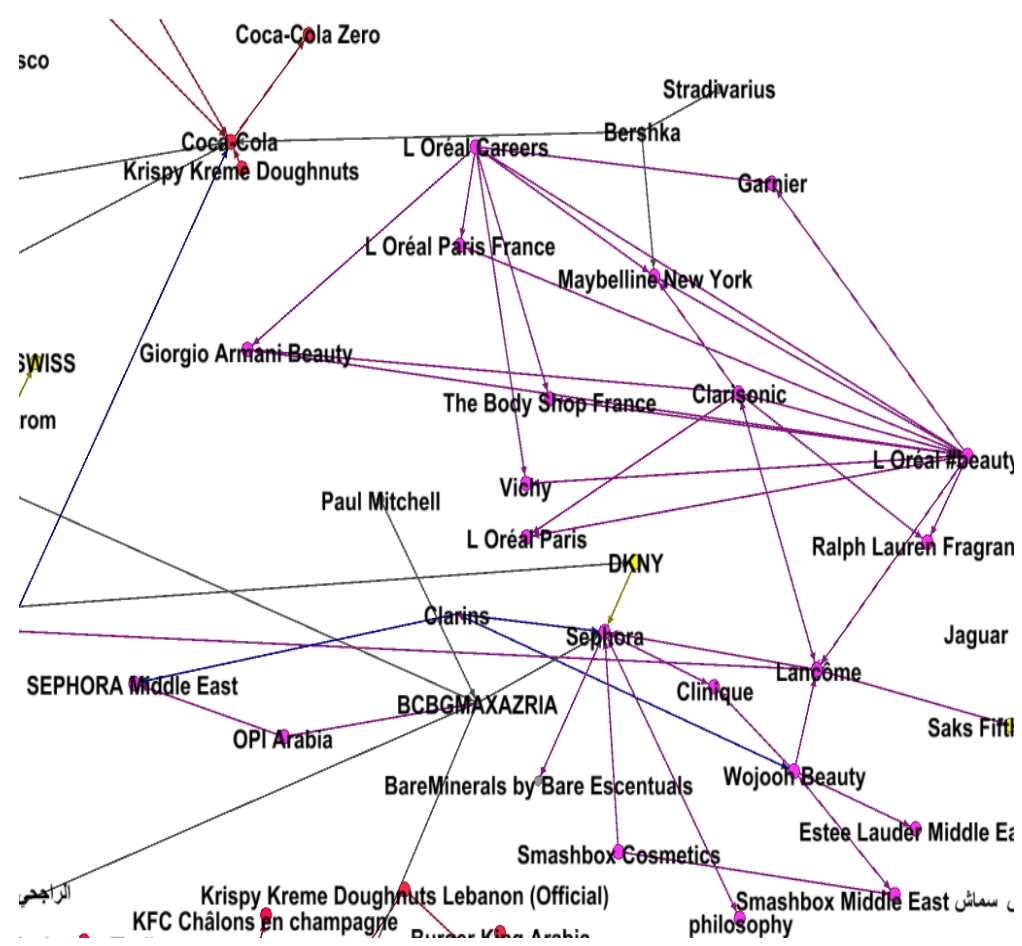

Figure 4. Close-up on gender-based network

Some of the smaller networks appeared that are not based on familial, industry, or gender factors. In such cases, geography, religion and culture played an important role in connecting brands-especially local brands that do not belong to a parent company and don't have branches around the world. For example, Figure 5 shows social networks of different brands that fall under different industries (Uturn-Entertainment, Talah Aljood-Dates, Tokyo Games-Video games, Abaya-Shampoo, Munch-Bakery, Pizza Fusion, Alireza Holding-industrial, Sayadiyah Express-seafood, Lifestyles-accessories, and Ta Marbota-women clothing). One explanation behind their connection is their geographic proximity to each other (see Figure 5).

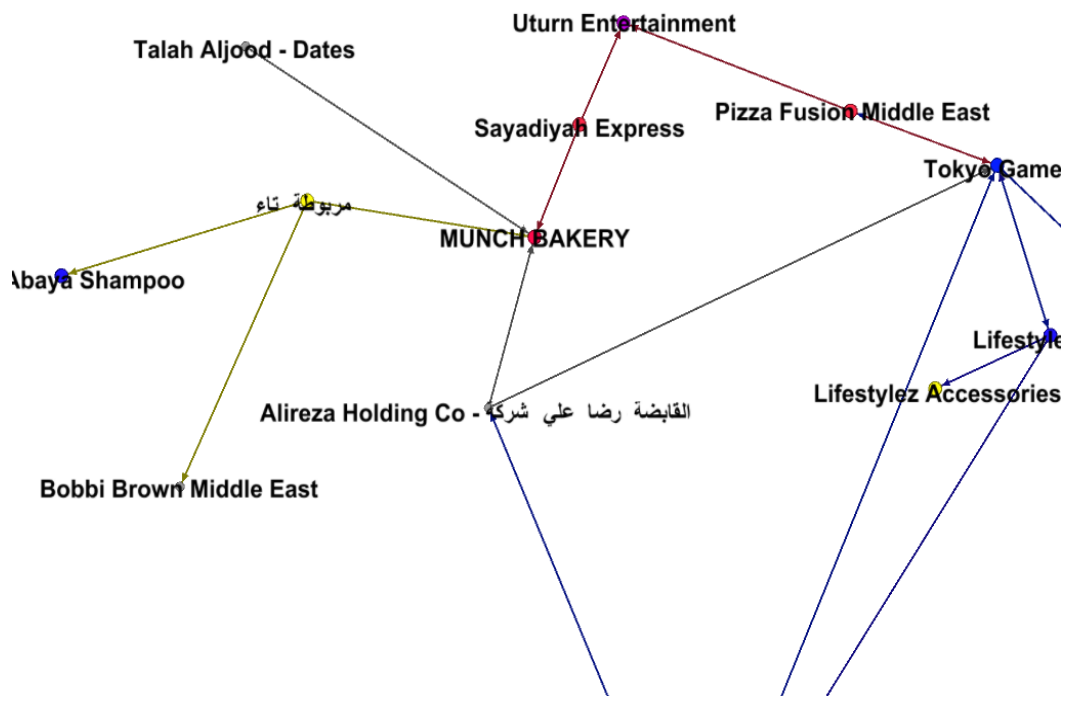

Figure 5. Close-up on geography/religion-based networks 


\section{Discussion}

This paper examined the page-like function in Facebook fan pages and how this function is used among local and global brands in Saudi Arabia. The findings of this study showed that global brands were more likely to connect to other brands that were under the same parent company, family value homophily. Although geographical similarities are one of the factors, brands that belong to the same family liked each other. This result could be due to an intentional strategic decision made by a social media division of the global conglomerates. Regardless, this result indicated that some types of value homophily can triumph the typical status homophilous relationships, e.g., geographical proximity, on social media network.

Among the studied Saudi brands, the brands that are not connected to family brands were more likely to connect with other brands that were under the same industry category, i.e., status homophily. The resulting graph indicated that the industry category was more important than other typical status homophilous relationships. On one hand, it made sense to have all brands that were in the similar industry connect with each other, but, on the other hand, the "likes" among the competing brands did not make sense. The closer look at Figure 3 showed, however, that the connections were not among brands that make cars. The important connector brands were promotion or distributor brands (e.g., Gold Rush Rally, Samaco Automotive) bridging the automotive brands together rather than each brand willingly connecting to other competing brands. It can be interpreted that those brands are positioned well in the structural holes (Burt, 1992; 2005) of this network. The interests of each company could be mediated by the distributor brands in this network. At least online, these companies are preventing the network from collapsing. Indeed, without these bridging brands, industry type connection could not have existed.

The findings also showed that the brands associated with women were more likely to connect with other brands that were also associated with women even if they were in different industry categories. Again, some brands, like Lancome, L'Oreal and Sephora, were bridging (i.e., high betweenness centrality) this group of brands. In terms of gender brand network in Saudi Arabia, some brands were better at connecting brands in the social media network. Maybe this is one of their strategies to occupy important network locations in their brand strategies.

In both automotive and women's brands network, it is important to recognize the importance of distributor brands. For example, Samaco Automotive and Sephora are brands specialized in distributing and selling the products. They do not need to have a special brand strategy only to connect to their own product because they do not have their own product. In fact, because they are distributors, they have incentives to connect to other brands. In terms of brands social network on Facebook, those distributors were placed in strategic locations that could decide the groupings of the relationships.

It was a surprise to find that geographic proximity played only a minor role in brand Facebook network in Saudi Arabia. But, it certainly connected brands mixed with religion especially when the brands did not belong to bigger family brands. The result indicated that some local brands were connected with religious affiliation when the stronger network homophily, i.e., industry type, brand family, did not exist.

\section{Limitation and Future Direction}

The uniqueness of this study focusing on brands' social network in Saudi Arabia is a strength and, at the same time, a weakness. Brands in different countries, even within the Arab world, could have different outcomes. Future studies can reveal value and status homophilous relationships among brands' networks in different countries and cultural settings. Further examination of homophily networks will benefit marketing practitioners since connecting to brands that have particular positions or importance in the network could reflect on the flow of information among brands, which can be reflected in what fans can see. Future studies can also investigate the direction of the edges which reflect if brands are mutually 'liking' each other or the relationship is unidirectional. The direction of the edge is important because only the 'liked' brand's Facebook fan page is visible to Facebook fans on the page of the brand that 'liked' the other brand. Another limitation is that this study is limited to brand's Facebook fan pages. Future research could consider examining networks among brands in different social media platforms such as Twitter. Different social media platforms could yield different results based on the nature of the platform. Facebook still has the highest number of users among the other social media platforms, however newer social media platforms such as Twitter are becoming more popular among different age groups which could influence brands to use different marketing strategies that are suitable for the audience of different social media platforms. Further, future studies could compare the homophilous relationships of brands online and offline and see if online and offline homophilous relationships are mirrored. 


\section{References}

Abuljadail, M., Ha, L., Wang, F., \& Yang, L. (2015). What Motivates Online Shoppers to "Like" Brands' Facebook Fan Pages? In M. Anabela \& T. Chia-Wen (Eds.), Human Behavior, Psychology and Social Interaction in the Digital Era. Hershey, PA: IGI Global. https://doi.org/10.4018/978-1-4666-8450-8.ch014

Badghish, S., Stanton, J., \& Hu, J. (2018). Consumer Complaint Behavior: A Comparison between Saudi Consumers and Filipino Migrants. Journal of Consumer Satisfaction, Dissatisfaction and Complaining Behavior, 31, 40-66.

Brandirectory. (2014). Global 500-2014. Retrieved April 19, 2015, from http://brandirectory.com/league_tables/table/global-500-2014

Burt, R. S. (1992). Structural holes: The social structure of competition. Cambridge, MA: Harvard Business Press.

Burt, R. S. (2005). Brokerage and closure: An introduction to social capital. New York: Oxford University Press.

De Chernatony, L. (2001). A model for strategically building brands. Journal of Brand, 9(4/5), 32-44. https://doi.org/10.1057/palgrave.bm.2540050

Digital Training Academy. (2015). Marketing Case: How Almarai inspired its fasting customers during Ramadan. $\quad$ Retrieved April $\quad 19, \quad 2015, \quad$ from http:/www.digitaltrainingacademy.com/casestudies/2015/02/content_marketing_case_study_how_almarai_ inspired_its_fasting_customers_during_ramadan.php

Facebook. (2015). Facebook newsroom. Retrieved April 19, 2015, from http://newsroom.fb.com/company-info/

Fuller, J. (2014). Here's what you need to know about the Hobby Lobby What are these cases about? The Washington Post.

Hansen, D., Shneiderman, B., \& Smith, M. A. (2011). Social network analysis: measuring, mapping, and modeling collections of connections (pp. 31-52). Analyzing social media networks with NodeXL: insights from a connected world. Elsevier Inc, Burlington. https://doi.org/10.1016/B978-0-12-817756-3.00003-0

Jeanjean, L. (2012). 5 tips to increase your Facebook fan base. Journal of Financial Planning, 1(1), $20-21$.

Kapferer, J. N. (2004). The New Strategic Brand Management. London: Kogan Page.

Lazarsfeld, P. F., \& Merton, R. K. (1954). Friendship as a social process: a substantive and method—ological analysis. In M. Berger (Ed.), Freedom and Control in Modern Society (pp. 18-66). New York: Van Nostrand.

Mahajan. (2013). Understanding the Arab consumer: a growing middle class that yearns for progress and modernity has no interest in abandoning its religious traditions. Harvard Business Review, 91(5), 128.

Marx, J. H., \& Spray, S. L. (1972). Psychotherapeutic "birds of a feather": Social-class status and religio-cultural value homophily in the mental health field. Journal of Health and Social Behavior, 413-428. https://doi.org/10.2307/2136834

McPherson, M., Smith-Lovin, L., \& Cook, J. M. (2001). Birds of a Feather: Homophily in Social Networks. Annual Review of Sociology, 27(1), 415-444. https://doi.org/10.1146/annurev.soc.27.1.415

Motion, J., Leitch, S., \& Brodie, J. R. (2003). Equity in corporate co-branding: the case of Adidas and the All Blacks. European Journal of Marketing, 37(7/8), 1080-1094. https://doi.org/10.1108/03090560310477672

Phillips, B. J., McQuarrie, E. F., \& Griffin, W. G. (2014). The Face of the Brand: How Art Directors Understand Visual Brand Identity. Journal of Advertising, 43(4), $318-332$. https://doi.org/10.1080/00913367.2013.867824

Stearns, E., Buchmann, C., \& Bonneau, K. (2009). Interracial friendships in the transition to college: do birds of a feather flock together once they leave the nest? Sociology of Education, 82(2), 173-195. https://doi.org/10.1177/003804070908200204

Stone, L. A. (2002). The Islamic crescent: Islam, culture and globalization. Innovation: The European Journal of Social Science Research, 15(2), 121-131. https://doi.org/10.1080/1351161022000001269

Top 100 saudibrands. (2013). Top 100 Saudi Brands. Retrieved April 19, 2015, from http:/www.top100saudibrands.com/awarded.html

Uggla, H. (2006). The corporate brand association base: A conceptual model for the creation of inclusive brand 
$\begin{array}{lllll}\text { architecture. } \quad \text { European } & \text { Journal } & \text { Marketing, } & \text { 40(7/8), }\end{array}$ https://doi.org/10.1108/03090560610669991

Wellman, B. (1996). Are personal communities local? A Dumptarian reconsideration. Soc. Networks, 18, 347-354. https://doi.org/10.1016/0378-8733(95)00282-0

$\mathrm{Xu}, \mathrm{C}$., Ryan, S., Prybutok, V., \& Wen, C. (2012). It is not for fun: An examination of social network site usage. Information \& Management, 49(5), 210-217. https://doi.org/10.1016/j.im.2012.05.001

\section{Appendix A}

\section{The Original 40 Brands in the Sample}

\begin{tabular}{ll}
\hline Local Brands & Global Brands \\
\hline Almarai & Sprite Middle East \\
Rabea Tea & KFC \\
Herfy & McDonalds \\
Kudu & Lays \\
Afia & Nescafe \\
Nada & Nestlé Desserts Arabia \\
Hana Water & Fanta Middle East \\
NADEC & Starbucks Middle East \\
Mikyajy & Lancome \\
Arabian Oud & Dove \\
Gazzaz & Garnier Arabia \\
ASQ - Abdul Samad Al Qurashi & Olay \\
Samaco Automotive & Toyota \\
Aljomaih Automotive Company & BMW \\
Al Rajhi Bank & American Express Saudi Arabia \\
Panda & Carrefour Saudi \\
Ahmed Abdulwahed Company & Samsung Saudi \\
eXtra Stores & Microsoft \\
AlShiaka & Ikea \\
Tokyo Games & PlayStation Middle East \\
20 brands & 20 brands \\
\hline
\end{tabular}

\section{Copyrights}

Copyright for this article is retained by the author, with first publication rights granted to the journal.

This is an open-access article distributed under the terms and conditions of the Creative Commons Attribution license (http://creativecommons.org/licenses/by/4.0/). 